\title{
ВИЗНАЧЕННЯ ВЕЛИЧИН КРИТИЧНИХ ДОВЖИН І РОЗКРИТТЯ ТРІЩИН В КОНСТРУКТИВНИХ ЕЛЕМЕНТАХ МЕТОДАМИ МЕХАНІКИ РУЙНУВАННЯ
}

\section{DETERMINATION OF CRITICAL LENGTH AND WIDTH OF CRACKS IN ELEMENTS OF STRUCTURE BY METHODS OF DESTRUCTION MECHANICS}

Ротко С.В., к.т.н., доц., Маткова А.В., к.т.н., доц., Швабюк В.В., к.т.н., доц., Токарев В.О., студент (Луцький національний технічний університет м. Луцьк)

Rotko S.V., Ph.D., associate professor, Matkova A.V., Ph.D., associate professor, Shvabyuk V.V., Ph.D., associate professor, Tokarev V.O., student (Lutsk National Technical University, Lutsk)

Проводяться дослідження граничного стану для елементів машин $i$ конструкцій з металу та залізобетону за різними методиками. Вважається, шьо згадані конструкиії можуть знаходитися під дією навантажень, котрі викликають позацентровий розтяг-стиск або згинальні деформації та пов'язані з ними пошкодження у вигляді трішин. Такі навантаження є особливо небезпечними і вимагають детальніших розрахунків методами механіки руйнування.

Prolonged operation of machines and structures often leads to a significant reduction in their load-bearing capacity. This is due to the appearance in the cross and longitudinal sections for various reasons of a large number of small cracks that can turn into trunk cracks. This can lead to the destruction of the structure itself.

Various methods are used to determine the ultimate state of metal or reinforced concrete structures that may be subjected to loads that cause eccentric tensile or compressive deformation and the associated formation of cracks. Such loads are especially dangerous and require more detailed calculations by methods of fracture mechanics. Different strength theories for brittle materials or fracture mechanics criteria can be used for such studies. The most common are the force criterion of J. Irwin, the deformation criterion of local destruction of M. Leonov, V. Panasyuk and D. Dagdale.

An important problem today is the assessment of the residual strength of structures damaged by defects such as cracks. An overview of the achievements on this problem can be found in the works of many famous scientists.

There are a large number of developed analytical and numerical methods for solving problems of crack theory, the solutions of which can investigate the crack resistance of materials and structures under different load conditions.

Criteria for linear fracture mechanics do not take into account a number of factors, ranging from the shape of the crack and ending with the history of formation of the material itself, its physical and mechanical characteristics and properties. For materials such as concrete and cast iron, it is necessary to use the criteria of nonlinear fracture 
mechanics, which take into account the nonlinearity of deformation and the heterogeneity of the material itself.

It is investigated that the accuracy of calculations of concrete and cast iron elements by methods of fracture mechanics depends on the knowledge of the real characteristics of crack resistance, obtained on the basis of modern methods.

Ключові слова: критерії руйнування, тріщина, параметри тріщуин, залищкова міциність.

Key words: fracture criteria, crack, crack parameters, residual strength.

Тривала експлуатація машин і конструкцій дуже часто призводить до значного пониження їх несучої здатності. Це пов'язане із появою у поперечних та поздовжніх перерізах, за різними причинами, значної кількості мілких тріщин, що мають властивість перетворюватися у магістральні. Останнє може загрожувати руйнуванням самої конструкції.

Розглядаються різні методики визначення граничного стану для конструкцій із металу або залізобетону, що можуть знаходитися під дією навантажень, котрі викликають позацентровий розтяг-стиск або згинальні деформації та пов'язані 3 ними пошкодження у вигляді тріщин. Такі навантаження $є$ особливо небезпечними і вимагають більш детальних розрахунків методами механіки руйнування. Для таких досліджень можуть використовуватися різні теорії міцності для крихких матеріалів або критерії механіки руйнування. Серед найбільш поширених таких критеріїв є силовий критерій Дж. Ірвіна [1] та деформаційні критерії локального руйнування М.Я. Леонова, В.В. Панасюка $-\delta_{c}$-критерій [2] та КРТ критерій Д.С. Дагдейла [3].

Важливою проблемою на сьогодні $є$ оцінка залишкової міцності конструкцій, що пошкоджені дефектами типу тріщин. Огляд досягнень 3 цієї проблеми можна знайти в роботах В.В. Панасюка, В.З. Партона, Є.О. Андрейківа, М.П. Саврука [4,5] та багатьох інших [6,7].

Існує велика кількість розроблених аналітичних і числових методів розв'язування задач теорії тріщин [8-11], на розв'язках яких можна дослідити тріщиностійкість матеріалів та конструкцій за різних умов навантаження.

Використаємо силовий критерій Дж. Ірвіна [1], який запропонував нову умову для визначення початку росту тріщини у деформованому твердому тілі. Запропонований ним критерій грунтується на концепції граничних значень коефіцієнтів інтенсивності напружень (КІН) $K_{i c}(i=I, I I, I I I), \quad$ де кожне значення індекса $i$ коефіцієнтів $K_{I}, K_{I I}, K_{I I I}$ пов'язане 3 типом зміщення берегів тріщини матеріалу елемента конструкції (рис.1). 

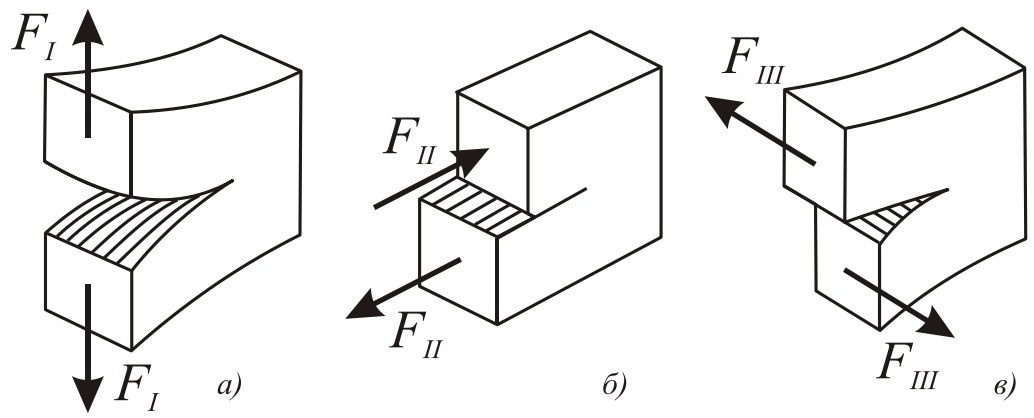

Рис. 1. Типи зміщення берегів тріщини: $a$ - розкриття (відрив);

$\sigma$ - поперечний зсув; 8 - поздовжній зсув

Сутність силового критерію полягає у тому, що початок розкриття і руху тріщини у кожному конкретному випадку (рис.1) починається 3 моменту, коли коефіцієнт інтенсивності напружень $K_{i}$ досягає свого граничного значення $K_{I c}$ (в'язкості руйнування):

$$
K_{i} \equiv(\sigma, \tau) \sqrt{\pi l} f_{i}(\lambda)=K_{i c},
$$

де $f_{i}(\lambda)$ - функція, за допомогою якої враховуються розміри елемента конструкції, спосіб його навантаження та форма тріщини. Для об'ємного приймають рівною одиниці, а згадані КІН спрощуються до формул:

$$
K_{I}=\sigma \sqrt{\pi l}, K_{I I, I I I}=\tau \sqrt{\pi l} .
$$

Знаючи експериментальні значення величин $K_{I c}$ для заданого матеріалу та використавши формули (1), (2) для різних типів руйнування, легко знайти значення критичних півдовжин тріщин $l_{\kappa p}$. за певного напруженого стану в тілі:

$$
l_{\kappa p .}=\frac{K_{I c}^{2}}{\pi \sigma^{2}} \text { i } l_{\kappa p .}=\frac{K_{I I c, I I I c}^{2}}{\pi \tau^{2}} .
$$

Після досягнення цих значень тріщина в матеріалі починає рухатися. Одночасно, використання цього методу має низку зауважень і недоліків, котрі пов'язані із вимогами і недоліками лінійної механіки руйнування та необхідністю переходу від однопараметричних критеріїв руйнування до їх багатопараметричних аналогів. 
Для бетону, чавуну та інших крихких матеріалів в'язкість руйнування $K_{I c}$ може приймати такі значення (табл.1).

Таблиця 1

Значення $\sigma_{\text {ми.p. }}, K_{I c}$ для деяких матеріалів

\begin{tabular}{|l|c|c|c|}
\hline \multicolumn{1}{|c|}{ Матеріал } & $\begin{array}{c}\sigma_{\text {мu.p }} \\
(\text { MПa) }\end{array}$ & $\begin{array}{c}E \cdot 10^{-4} \\
(M \Pi a)\end{array}$ & $\begin{array}{c}K_{I c} \\
(M \Pi a \sqrt{\mathcal{M}})\end{array}$ \\
\hline Алюміній (стоп Д16T) & 209 & 7,1 & 43,4 \\
Кераміка $\left(\mathrm{Al}_{2} \mathrm{O}_{3}\right)$ & 120 & 3,82 & 6 \\
Феритний чавун & 230 & 15,5 & 16 \\
Бетон $(C 25 / 30)$ & 1,2 & 3,25 & 0,72 \\
\hline
\end{tabular}

До одного із таких, більш досконалих, методів належать деформаційні критерій локального руйнування - $\delta_{c}$-критерій, запропонований М. Леоновим, В. Панасюком та Д. Дагдейлом [2,3]. Ці критерії дають змогу визначити критичне напруження $\sigma_{\kappa p}$. за величиною розкриття вістря тріщини $\delta_{I}$ у пружно-пластичному матеріалі (рис. 2).

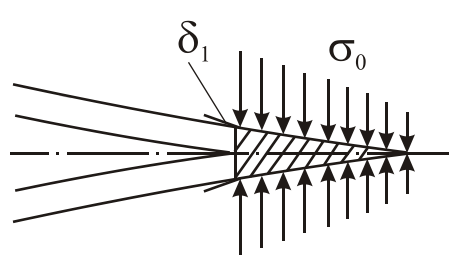

a)

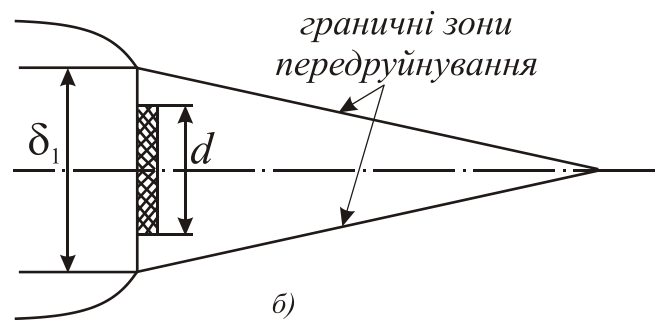

б)

Рис. 2. Розрахункова схема деформаційного критерію

За цим критерієм вважається, що умовою руйнування матеріалу $є$ досягнення величиною розкриття тріщини $\delta_{I}$ певного критичного значення $\delta_{\text {Ic }}$ :

$$
\delta_{I}=\delta_{I c} .
$$

Тут $\delta_{I c}=\left(1+\varepsilon_{c}\right) d-$ константа матеріалу, яка фіксується в момент зрушення (початку руху) тріщини; $\mathcal{E}_{c}$ - граничне значення деформації, за 
якої відбувається розрив матеріалу; $d$ - певна початкова довжина елемента матеріалу в зоні передруйнування (рис. 26).

Величину розкриття тріщини $\delta_{I}$ шукають за допомогою наближеної формули [5]:

$$
\delta_{I}=\frac{\pi \sigma^{2} l}{E \sigma_{0}}
$$

де $\sigma_{0}-$ усереднене напруження, яке знаходиться у межах $\sigma_{\text {пл. }} \leq \sigma_{0} \leq 0,5\left(\sigma_{n л .}+\sigma_{\text {ми. }}\right)$.

Використовуючи формули (4), (5) легко отримати вираз для критичного значення півдовжини тріщини $l_{\kappa p}$.

$$
l_{\kappa p .}=\frac{E \sigma_{0} \delta_{I c}}{\pi \sigma^{2}}
$$

Одночасно, між характеристиками в'язкості руйнування матеріалу $K_{I c}, K_{I I c} i K_{\text {IIIc }}$ та відповідними величинами розкриття тріщини існує взаємозв'язок у вигляді наступних формул:

$$
\delta_{I c}=\frac{K_{I c}^{2}}{\sigma_{0} E} ; \quad \delta_{I I c}=\frac{K_{I I c}^{2}}{\tau_{0} G} \cdot(1-v) ; \quad \delta_{I I I c}=\frac{2 K_{I I I c}^{2}}{\pi \tau_{0} G} .
$$

У випадку пружно-пластичного матеріалу у формулах (7) iз невеликою похибкою можна прийняти, що відповідні напруження $\sigma_{0} \mathrm{i}$ $\tau_{0}$ дорівнюють відповідним границям плинності: $\sigma_{0}=\sigma_{0,2}$ i $\tau_{0}=\tau_{0,2}$. Для крихкого матеріалу такі спрощення уже не є допустимими.

Разом 3 тим, для визначення критичного значення півдовжини тріщини $l_{\kappa p}$. при заданому напруженні $\sigma$ у формулі (6), необхідно знати або його величину, або яку частину $m$ від граничного $\left(M_{u}, P_{u}, q_{u}\right)$ складає діюче навантаження $(M, P, q)$. Після цього необхідно у формулу (6) замість величини $\sigma$ підставити величину $\sigma_{0} / m$. Тоді згадана формула, із урахуванням (7), набуде вигляду:

$$
l_{\kappa p .}=\frac{m^{2} K_{I C}^{2}}{\pi \sigma_{0}^{2}}
$$


Дані формули є дуже наближеними, бо не враховують у лінійній механіці руйнування низки факторів, починаючи від форми тріщини i закінчуючи історією формування самого матеріалу, його фізичними та механічними характеристиками та властивостями. Для точніших підрахунків необхідно використовувати критерії нелінійної механіки руйнування у бетонах, чавунах і стопах $[5,6,7]$. Ці критерії враховують обов'язково як нелінійність деформування, так і неоднорідність самого матеріалу.

Таким чином, використавши формули (7), (8), а також дані табл.1, можна отримати значення критичних півдовжин тріщин $\tilde{l}_{\kappa p .}=l_{\kappa p} / m^{2} \mathrm{i}$ величини критичного розкриття $\delta_{I c}$ за розглянутими методами та звести ці результати у табл. 2.

Таблиця 2

Значення $\tilde{l}_{\kappa p .}$ та $\delta_{I c}$ для заданих матеріалів

\begin{tabular}{|l|c|c|}
\hline \multicolumn{1}{|c|}{ Матеріал } & $\begin{array}{c}\tilde{l}_{\kappa p .} \\
(м \mu)\end{array}$ & $\begin{array}{c}\delta_{I c} \\
(м м)\end{array}$ \\
\hline Алюміній & 13,7 & 0,127 \\
(стоп Д16T) & 0,80 & 0,0078 \\
Кераміка $\left(\mathrm{Al}_{2} \mathrm{O}_{3}\right)$ & 1,54 & 0,0072 \\
Феритний чавун & 114,6 & 0,0133 \\
Бетон $(C 25 / 30)$ & & \\
\hline
\end{tabular}

Потрібно зауважити, що дані першого стовпця необхідно ще домножити на параметр $m^{2}$, який для кожного матеріалу буде своїм. Дані другого стовпця містять значення величини критичного розкриття $\delta_{\text {Ic }}$ у міліметрах. Зокрема, для алюмінієвого стопу Д16Т (перший рядок) ці дані майже співпадають із відповідним результатом Я.Л. Іваницького і П.С. Куня [12, с.173], де для початкової довжини півтріщини $l_{0}=13$ мм знайдено величину критичного розкриття $\delta_{I c}=0,125$ мм. Дані, що отримані для бетону (остання стрічка), повністю співпадають із даними роботи [13, с. 247, табл.3], одержаними за енергетичним методом $\left(\delta_{c}^{e}=0,013\right.$ мм ).

Одночасно, із аналізу даних другого стовпця видно, що величина критичного розкриття $\delta_{\text {Ic }}$ для бетону $\mathrm{C} 25 / 30 €$ явно заниженою у 
порівнянні $з$ експериментальними даними. Так, згідно Y. Jeng i S.P. Shah [7, с.287] експериментальна величина критичного розкриття становить $\delta_{I c}=0,125 \mathrm{Mм}$ для бетону C25/30 (з урахуванням повзучості та усадки протягом 28 діб), що є більшим у 9,4 разів. Аналогічні дослідження проводилися Й.Й. Лучком, П.М. Ковалем і С.Т. Штаюрою [13], де для подібних бетонів в'язкість руйнування уже дорівнює $K_{I C}^{p}=1,82$. У цьому випадку за формулою (7) відповідний результат буде $\delta_{I c}=0,085$ мм, що дає похибку $32 \%$.

Тобто, точність розрахунків елементів конструкцій із бетону та чавуну методами механіки руйнування залежить від знання реальних характеристик тріщиностійкості, отриманих на основі сучасних методик, із урахуванням часового періоду та закономірностями їх зміни через певний час.

\section{References}

1. Irwin G.R. Analysis of stresses and strains near the end of a crack traversing a plate // J. Appl. Mech, 1957. 24. P/ 361-364.

2. Leonov M.Ia., Panasiuk V.V. Rozvytok naidribnishykh trishchyn v tverdomu tili // Prykladna mekhanika, 1959. №4. S. 391- 401.

3. Dugdale D.S., Yielding of steel sheets containing slits. J. Mech. And Phys. Sol., 8 (1960) pp. 100-108.

4. Mekhanyka razrushenyia y prochnost materyalov: Sprav. posobye: V 4-kh tomakh / Pod obshchei red. Panasiuka V.V. Kyev: Nauk. dumka. 1988. T.1: Osnovy mekhanyky razrushenyia / Panasiuk V.V., Andreikyv A.E., Parton V.Z., 1988. 488 s. T.2: Koeffytsyenty yntensyvnosty napriazhenyi $\mathrm{v}$ telakh $\mathrm{s}$ treshchynamy / Savruk M.P., $1988,620 \mathrm{~s}$.

5. Panasiuk V.V. Mekhanyka kvazykhrupkoho razrushenyia materyalov. K.: Nauk. dumka, 1991. $146 \mathrm{~s}$.

6. Pyradov K.A. Bysenov K.A., Abdullaev K.U. Mekhanyka razrushenyia betona y zhelezobetona. ALMATY: Yzd. tsentr VAK RK Mynobrazovanyia y nauky RK, 2000. $305 \mathrm{~s}$.

7. Luchko Y.I., Chubrikov V.M., Lazar V.F. Mitsnist, trishchynostiikist i dovhovichnist betonnykh ta zalizobetonnykh konstruktsii na zasadakh mekhaniky ruinuvannia. Lviv: Kameniar, 1999. $348 \mathrm{~s}$.

8. Sulym H., Rotko S., Shvabiuk V. Strength of composite ring damaged by a crack // Materialy IV Sympozjum Mechaniki Zniszczenia Materialow i Konstrukcji. Augustow, 2007. P. 261-263.

9. Shvabiuk V.I., Rotko S.V. Liniine deformuvannia, mitsnist i stiikist kompozytnykh obolonok serednoi tovshchyny: monohrafiia, Lutsk, 2015. $264 \mathrm{~s}$.

10. Spravochnyk po koeffytsyentam yntensyvnosty napriazhenyi: V 2-kh tomakh: Per. s anhl. / Pod red. Yu. Murakamy. M.: Myr, 1990. 1016 s.

11. Shvabiuk V.I. Opir materialiv: Pidruchnyk. Kyiv: Znannia, 2016. 408 s.

12. Ivanytskyi Ya.L., Kun P.S. Trishchynostiikist konstruktsiinykh materialiv za skladnoho navantazhennia. Lviv: SPOLOM, $2013.280 \mathrm{~s}$. 
13. Luchko Y.I., Koval P.M., Shtaiura S.T. Porivniannia sylovoho ta enerhetychnoho pidkhodiv pid chas vyznachennia kharakterystyk trishchynostiikosti betonu // Mekhanika i fizyka ruinuvannia budivelnykh materialiv ta konstruktsii /Za zah. red. Andreikiva A.Ie., Luchka Y.I., Bozhydarnyka V.V. Lviv: Kameniar. 2002. 585 s.

\section{Список літератури}

1. Irwin G.R. Analysis of stresses and strains near the end of a crack traversing a plate // J. Appl. Mech, 1957. 24. P/ 361-364.

2. Леонов М.Я., Панасюк В.В. Розвиток найдрібніших тріщин в твердому тілі // Прикладна механіка, 1959. №4. С. 391- 401.

3. Dugdale D.S., Yielding of steel sheets containing slits. J. Mech. And Phys. Sol., 8 (1960) pp. 100-108.

4. Механика разрушения и прочность материалов: Справ. пособие: В 4-х томах / Под общей ред. Панасюка В.В. Киев: Наук. думка. 1988. Т.1: Основы механики разрушения / Панасюк В.В., Андрейкив А.Е., Партон В.3., 1988. 488 с. T.2: Коэффициенты интенсивности напряжений в телах с трещинами / Саврук М.П.,1988, 620 c.

5. Панасюк В.В. Механика квазихрупкого разрушения материалов. К.: Наук. думка, 1991. 146 с.

6. Пирадов К.А. Бисенов К.А., Абдуллаев К.У. Механика разрушения бетона и железобетона. АЛМАТЫ: Изд. центр ВАК РК Минобразования и науки РК, 2000. $305 \mathrm{c}$.

7. Лучко Й.Й., Чубріков В.М., Лазар В.Ф. Міцність, тріщиностійкість і довговічність бетонних та залізобетонних конструкцій на засадах механіки руйнування. Львів: Каменяр, 1999. 348 с.

8. Sulym H., Rotko S., Shvabiuk V. Strength of composite ring damaged by a crack // Materialy IV Sympozjum Mechaniki Zniszczenia Materialow i Konstrukcji. Augustow, 2007. P. 261-263.

9. Шваб’юк В.І., Ротко С.В. Лінійне деформування, міцність і стійкість композитних оболонок середньої товщини: монографія, Луцьк, 2015. 264 с.

10. Справочник по коэффициентам интенсивности напряжений: В 2-х томах: Пер. с англ. / Под ред. Ю. Мураками. М.: Мир, 1990. 1016 с.

11. Шваб’юк В.І. Опір матеріалів: Підручник. Київ: Знання, 2016. 408 с.

12. Іваницький Я.Л., Кунь П.С. Тріщиностійкість конструкційних матеріалів за складного навантаження. Львів: СПОЛОМ, 2013.280 с.

13. Лучко Й.Й., Коваль П.М., Штаюра С.Т. Порівняння силового та енергетичного підходів під час визначення характеристик тріщиностійкості бетону // Механіка і фізика руйнування будівельних матеріалів та конструкцій /За заг. ред. Андрейківа А.С., Лучка Й.Й., Божидарника В.В. Львів: Каменяр. 2002. 585 с. 